\title{
Characterization of four new antifungal yanuthones from Aspergillus niger
}

\author{
Lene M Petersen ${ }^{1,6}$, Dorte K Holm ${ }^{2,6}$, Peter B Knudsen ${ }^{3}$, Kristian F Nielsen ${ }^{4}$, Charlotte H Gotfredsen ${ }^{5}$, \\ Uffe H Mortensen $^{2}$ and Thomas O Larsen ${ }^{1}$
}

Four new yanuthone analogs (1-4) were isolated from the filamentous fungus Aspergillus niger. The structures of the new compounds were elucidated on the basis of UHPLC-DAD-HRMS data and one-dimensional and two-dimensional NMR spectroscopy. Labeling studies with ${ }^{13} \mathrm{C}_{8}-6$-methylsalicylic acid identified three class I yanuthones originating from the polyketide 6-methylsalicylic acid (yanuthone $\mathrm{K}, \mathrm{L}$ and $\mathrm{M}(1-3)$ ) and a class II yanuthone, which was named yanuthone $\mathrm{X}_{2}(4)$. The four new compounds were tested toward the pathogenic yeast Candida albicans and all displayed antifungal activity. Yanuthone $\mathrm{X}_{2}$ represents the first example of a bioactive class II yanuthone, demonstrating the pharmaceutical potential of this class.

The Journal of Antibiotics (2015) 68, 201-205; doi:10.1038/ja.2014.130; published online 8 October 2014

\section{INTRODUCTION}

The black fungus Aspergillus niger is a significant contaminant of food and feeds, and a widely used cell factory for production of citric acid and bulk enzymes. ${ }^{1,2}$ In this context it is important to note that A. niger is known to produce $>100$ secondary metabolites, ${ }^{3}$ including not only mycotoxins such as ochratoxin A and fumonisins, ${ }^{3-8}$ but also medically relevant compounds such as asperpyrone B and yanuthones targeting C. albicans. ${ }^{9,10}$ Recently, access to the full genome of A. niger ${ }^{11,12}$ has provided a platform that allows for linking genes to specific secondary metabolites. To this end, we have recently reported the characterization of the biosynthetic pathway toward antimicrobial yanuthone $\mathrm{D}$ in $A$. niger. $^{13}$

The core structure of yanuthones constitutes an epoxylated sixmembered ring, which may be further decorated with different side chains: one sesquiterpene (at C13) and varying side chains (at C15 and C16), see Figure 1. The core structure may be derived from at least two different precursors, which lead to the formation of two classes of yanuthones. Class I yanuthones are derived from the polyketide 6-methylsalicylic acid (6-MSA), which due to a decarboxylation event during yanuthone formation, delivers a six-membered methylated ring (a $\mathrm{C}_{7}$ scaffold) to the yanuthones. Class II yanuthones contains a $\mathrm{C}_{6}$-core scaffold derived from an unknown precursor. ${ }^{13}$ The additional methyl group in class I yanuthones controls what type of decoration is possible at C16. Despite derivation of the two classes of yanuthones from different precursors, they share downstream enzymatic activities toward product maturation. So far, 15 class I yanuthones and a single class II yanuthone have been described in the literature of which only yanuthone D, a class I yanuthone, has displayed strong antimicrobial activity. $9,13,14$

These observations prompted us to investigate whether additional yanuthones exist in A. niger and whether such new compounds display antimicrobial activity. C. albicans accounts for the highest source of fungal infections worldwide, ${ }^{15}$ which is why it is of great interest to find new drug candidates. Here, we report the structures of four new yanuthones and their bioactivities toward C. albicans.

\section{RESULTS AND DISCUSSION}

Identification and structural elucidation of four new yanuthones Inspired by our previous discovery of six new yanuthones in A. niger, ${ }^{13}$ the A. niger strain KB1001 was cultivated on YES, and a large extract was scrutinized for compounds that could potentially be new yanuthones. The UHPLC-DAD-HRMS analysis tentatively identified four yanuthone-related structures. Their UV spectra as well as chemical compositions indicated coherence to the previously identified structures., ${ }^{9,13,14}$ The four compounds were purified and their structures elucidated from the HR-MS data, UV data and one-dimensional and two-dimensional (2D) NMR experiments (see Tables 1 and 2 and further details in the Supplementary Information).

All structures contain a six-membered ring containing an epoxide, which defines the core structure of yanuthones, but vary in their side chains, see Figure 1. Importantly, three of the compounds

\footnotetext{
${ }^{1}$ Chemodiversity Group, Department of Systems Biology, Technical University of Denmark, Kongens Lyngby, Denmark; ${ }^{2}$ Eukaryotic Molecular Cell Biology Group, Department of Systems Biology, Technical University of Denmark, Kongens Lyngby, Denmark; ${ }^{3}$ Fungal Physiology and Biotechnology Group, Department of Systems Biology, Technical University of Denmark, Kongens Lyngby, Denmark; ${ }^{4}$ Metabolic Signaling and Regulation Group, Department of Systems Biology, Technical University of Denmark, Kongens Lyngby, Denmark and ${ }^{5}$ Department of Chemistry, Technical University of Denmark, Kongens Lyngby, Denmark

6These authors contributed equally to this work.

Correspondence: Dr Professor TO Larsen, Chemodiversity Group, Department of Systems Biology, Technical University of Denmark, Soeltofts Plads B221, Kongens Lyngby DK-2800, Denmark.

E-mail: tol@bio.dtu.dk

Received 29 April 2014; revised 18 June 2014; accepted 14 August 2014; published online 8 October 2014
} 


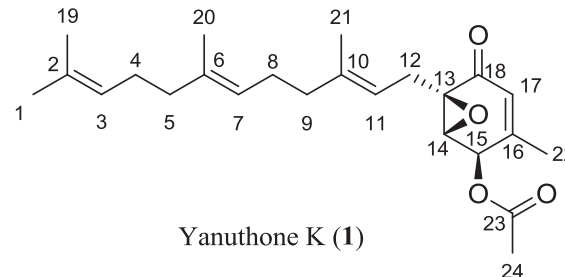<smiles></smiles><smiles>CC(=O)O[C@@H]1C(C)=CC(=O)[C@@]2(C/C=C(\C)CC/C=C(/C)CC/C=C(\C)CO)O[C@@H]12</smiles><smiles>COC1=CC(=O)[C@@]2(C/C=C(\C)CC/C=C(\C)CCC=C(C)C)OC1[C@@H]2O</smiles>

Yanuthone $\mathrm{X}_{2}(\mathbf{4})$

Figure 1 Structures of the four new compounds yanuthone $\mathrm{K}-\mathrm{M}$ and $\mathrm{X}_{2}$.

Table $1{ }^{1} \mathrm{H}$ NMR chemical shift (p.p.m.), integral, multiplicity and $J$ coupling constants $(\mathrm{Hz})$ for yanuthone $\mathrm{K}-\mathrm{M}$ and $\mathrm{X}_{2}$

\begin{tabular}{|c|c|c|c|c|}
\hline $\begin{array}{l}\text { Atom } \\
\#\end{array}$ & Yanuthone K (1) & Yanuthone L (2) & Yanuthone M (3) & Yanuthone $X_{2}(4)$ \\
\hline 1 & $1.65(3 \mathrm{H}, \mathrm{s})$ & $3.84(2 \mathrm{H}, \mathrm{s})$ & $1.11(3 \mathrm{H}, \mathrm{m})$ & $1.66(3 \mathrm{H}, \mathrm{d}, 0.9)$ \\
\hline 2 & - & - & - & - \\
\hline 3 & $5.08(1 \mathrm{H}, \mathrm{m})$ & $\begin{array}{c}5.32(1 \mathrm{H}, \mathrm{tq}, 7.0 \\
1.4)\end{array}$ & $1.34(2 \mathrm{H}, \mathrm{m})$ & $5.09(1 \mathrm{H}, \mathrm{m})$ \\
\hline 4 & $2.02(2 \mathrm{H}, \mathrm{m})$ & $2.08(2 \mathrm{H}, \mathrm{m})$ & $1.41(2 \mathrm{H}, \mathrm{m})$ & $2.05(2 \mathrm{H}, \mathrm{m})$ \\
\hline 5 & $1.94(2 \mathrm{H}, \mathrm{m})$ & $1.99(2 \mathrm{H}, \mathrm{m})$ & $1.93(2 \mathrm{H}, \mathrm{m})$ & $1.95(2 \mathrm{H}, \mathrm{m})$ \\
\hline 6 & - & - & - & - \\
\hline 7 & $5.07(1 \mathrm{H}, \mathrm{m})$ & $\begin{array}{c}5.09(1 \mathrm{H}, \mathrm{tq}, 7.0 \\
1.3)\end{array}$ & $5.08(1 \mathrm{H}, \mathrm{m})$ & $5.08(1 \mathrm{H}, \mathrm{m})$ \\
\hline 8 & $2.06(1 \mathrm{H}, \mathrm{m})$ & $2.07(2 \mathrm{H}, \mathrm{m})$ & $2.07(2 \mathrm{H}, \mathrm{m})$ & $2.07(2 \mathrm{H}, \mathrm{m})$ \\
\hline $8^{\prime}$ & $2.00(1 \mathrm{H}, \mathrm{m})$ & & & \\
\hline 9 & - & $1.991(2 \mathrm{H}, \mathrm{m})$ & $2.00(2 \mathrm{H}, \mathrm{m})$ & $1.99(2 \mathrm{H}, \mathrm{m})$ \\
\hline 10 & - & - & - & - \\
\hline 11 & $5.01(1 \mathrm{H}, \mathrm{m})$ & $5.01(1 \mathrm{H}, \mathrm{m})$ & $5.02(1 \mathrm{H}, \mathrm{m})$ & $5.04(1 \mathrm{H}, \mathrm{m})$ \\
\hline 12 & $\begin{array}{c}2.69(1 \mathrm{H}, \mathrm{dd} \\
15.3,8.1)\end{array}$ & $\begin{array}{c}2.69(1 \mathrm{H}, \mathrm{dd} \\
15.6,8.2)\end{array}$ & $\begin{array}{c}2.69(1 \mathrm{H}, \mathrm{dd} \\
15.4,8.1)\end{array}$ & $\begin{array}{c}2.74(1 \mathrm{H}, \mathrm{dd} \\
15.0,8.1)\end{array}$ \\
\hline $12^{\prime}$ & $\begin{array}{c}2.45(1 \mathrm{H}, \mathrm{dd} \\
15.4,6.7)\end{array}$ & $\begin{array}{c}2.45(1 \mathrm{H}, \mathrm{dd} \\
15.5,6.7)\end{array}$ & $\begin{array}{c}2.45(1 \mathrm{H}, \mathrm{dd} \\
15.4,6.7)\end{array}$ & $\begin{array}{c}2.36(1 \mathrm{H}, \mathrm{dd} \\
15.0,6.6)\end{array}$ \\
\hline 13 & - & - & - & - \\
\hline 14 & $3.65(1 \mathrm{H}, \mathrm{d}, 2.6)$ & $3.66(1 \mathrm{H}, \mathrm{d}, 2.6)$ & $3.66(1 \mathrm{H}, \mathrm{d}, 2.6)$ & $3.58(1 \mathrm{H}, \mathrm{d}, 3.1)$ \\
\hline 15 & $5.80(1 \mathrm{H}, \mathrm{m})$ & $5.80(1 \mathrm{H}, \mathrm{m})$ & $5.81(1 \mathrm{H}, \mathrm{m})$ & $4.58(1 \mathrm{H}, \mathrm{d}, 2.9)$ \\
\hline 16 & - & - & - & - \\
\hline 17 & $5.81(1 \mathrm{H}, \mathrm{m})$ & $5.81(1 \mathrm{H}, \mathrm{m})$ & $5.82(1 \mathrm{H}, \mathrm{m})$ & $5.18(1 \mathrm{H}, \mathrm{s})$ \\
\hline 18 & - & - & - & - \\
\hline 19 & $1.59(3 \mathrm{H}, \mathrm{s})$ & $1.591(3 \mathrm{H}, \mathrm{s})$ & $1.11(3 \mathrm{H}, \mathrm{s})$ & $1.59(3 \mathrm{H}, \mathrm{s})$ \\
\hline 20 & $1.58(3 \mathrm{H}, \mathrm{s})$ & $1.59(3 \mathrm{H}, \mathrm{s})$ & $1.57(3 \mathrm{H}, \mathrm{s})$ & $1.58(3 \mathrm{H}, \mathrm{s})$ \\
\hline 21 & $1.62(3 \mathrm{H}, \mathrm{s})$ & $1.62(3 \mathrm{H}, \mathrm{s})$ & $1.62(3 \mathrm{H}, \mathrm{s})$ & $1.62(3 \mathrm{H}, \mathrm{s})$ \\
\hline 22 & $1.84(3 \mathrm{H}, \mathrm{s})$ & $1.84(3 \mathrm{H}, \mathrm{t}, 1.22)$ & $1.85(3 \mathrm{H}, \mathrm{m})$ & $3.69(3 \mathrm{H}, \mathrm{s})$ \\
\hline 23 & - & - & - & \\
\hline 24 & $2.16(3 \mathrm{H}, \mathrm{s})$ & $2.16(3 \mathrm{H}, \mathrm{s})$ & $2.16(3 \mathrm{H}, \mathrm{s})$ & \\
\hline
\end{tabular}

Spectra were referenced by solvent signals for $\mathrm{CD}_{3} \mathrm{CN}$ at $\delta_{\mathrm{H}}=1.94$ p.p.m.

(yanuthones $\mathrm{K}-\mathrm{M}(\mathbf{1}-\mathbf{3})$ ) contain a $\mathrm{C}_{7}$ core associated with class I yanuthones, whereas the remaining yanuthone $\mathrm{X}_{2}(4)$ contain a $\mathrm{C}_{6}$ core scaffold characteristic for class II yanuthone, hence representing the second compound of this class.
Table $2{ }^{13} \mathrm{C}$ NMR chemical shifts (p.p.m.) for yanuthone $\mathrm{K}-\mathrm{M}$ and $\mathrm{X}_{2}$

\begin{tabular}{|c|c|c|c|c|}
\hline Atom \# & 1 & 2 & 3 & 4 \\
\hline 1 & 25.7 & 68.1 & 29.2 & 25.8 \\
\hline 2 & 132.0 & 136.1 & 70.7 & 132.1 \\
\hline 3 & 125.1 & 125.1 & 43.9 & 124.9 \\
\hline 4 & 27.5 & 26.8 & 23.2 & 27.3 \\
\hline 5 & 40.4 & 40.0 & 40.5 & 40.4 \\
\hline 6 & 136.1 & 135.9 & 136.4 & 136.0 \\
\hline 7 & 125.1 & 124.7 & 124.7 & 124.8 \\
\hline 8 & 27.4 & 26.8 & 26.9 & 27.3 \\
\hline 9 & 40.4 & 40.0 & 40.3 & 40.4 \\
\hline 10 & 140.4 & 140.1 & 140.3 & 139.7 \\
\hline 11 & 117.6 & 117.4 & 117.3 & 118.1 \\
\hline 12 & 26.5 & 26.4 & 26.3 & 27.1 \\
\hline 13 & 61.0 & 61.0 & 60.8 & 61.1 \\
\hline 14 & 57.2 & 57.1 & 57.2 & 58.9 \\
\hline 15 & 69.6 & 69.4 & 69.5 & 65.9 \\
\hline 16 & 153.9 & 153.8 & 153.7 & 172.6 \\
\hline 17 & 125.2 & 124.9 & 124.9 & 98.8 \\
\hline 18 & 194.1 & 194.1 & 194.2 & 194.4 \\
\hline 19 & 17.6 & 13.6 & 29.2 & 17.7 \\
\hline 20 & 16.0 & 15.8 & 15.8 & 16.2 \\
\hline 21 & 16.2 & 16.4 & 16.3 & 16.4 \\
\hline 22 & 19.8 & 19.6 & 19.6 & 57.1 \\
\hline 23 & 171.2 & 171.4 & 171.0 & \\
\hline 24 & 20.8 & 20.8 & 20.8 & \\
\hline
\end{tabular}

Spectra were referenced by solvent signals for $\mathrm{CD}_{3} \mathrm{CN}$ at $\delta_{\mathrm{C}}=1.32,118.26$ p.p.m.

All four yanuthones showed several similar features in the ${ }^{1} \mathrm{H}$, as well as $2 \mathrm{D}$ spectra. All displayed eight overlapping proton resonances at $\delta_{\mathrm{H}}=1.41-2.08$ p.p.m. in the ${ }^{1} \mathrm{H}$ spectrum, corresponding to the four methylene groups at $\mathrm{C} 4, \mathrm{C} 5, \mathrm{C} 8$ and $\mathrm{C} 9$, present in all structures. Other common resonances were seen for the diastereotopic pair H12/ H12' and the three methyl groups (H19, H2O and H21) around $\delta_{\mathrm{H}}=1.60$ p.p.m., of which $\mathrm{H} 20$ and $\mathrm{H} 21$ were overlapping. Moreover, all four yanuthones showed $\mathrm{HMBC}$ correlations to a quaternary carbon $(\mathrm{C} 18)$ around $\delta_{\mathrm{C}}=194$ p.p.m., as well as two carbons around $\delta_{\mathrm{C}}=60$ p.p.m. (one quaternary, one methine) being the carbons in the epoxide ring. 
The moiety attached to $\mathrm{C} 15$ varied, with yanuthone $\mathrm{K}-\mathrm{M}$ having an acetoxy group attached (as also seen for yanuthone $C^{9}$ ), whereas yanuthone $\mathrm{X}_{2}$ had a hydroxyl group (as seen in yanuthone $\mathrm{A}$ and $\mathrm{E}^{9}$ ). The structures also showed variance regarding the group attached to C16. Yanuthone $\mathrm{K}-\mathrm{M}$ had a methyl group, whereas yanuthone $\mathrm{X}_{2}$ differed in having a methoxy group attached at the $\mathrm{C} 16$ position. This was obvious from the chemical shift of $\mathrm{C} 16$, which gave rise to a resonance at $\delta_{\mathrm{C}}=172.6$ p.p.m., considerably further downfield than in the other structures (yanuthone K-M). Furthermore, C17 was affected, shifting upfield to $\delta_{\mathrm{C}}=98.8$ p.p.m. As expected, the chemical shifts of the core structure of yanuthone $\mathrm{K}-\mathrm{M}$ are very similar, whereas yanuthone $\mathrm{X}_{2}$ differs especially around position C16.

The attached terpene chain also varied in the four structures. Yanuthone $\mathrm{K}$ and $\mathrm{X}_{2}$ proved to contain a non-modified sesquiterpene. Yanuthone $\mathrm{L}$ and $\mathrm{M}$ also contain a sesquiterpene chain, but this is oxidized at $\mathrm{C} 1$ and $\mathrm{C} 2$, respectively.

NOESY experiments enabled determination of the stereogenic centers of 1-4 to be similar to the previously described yanuthones. For all four yanuthones the NOESY data showed a strong correlation between H14 and H15 (see Supplementary Information), suggesting these protons to be on the same side of the six-membered ring. This was further supported by the optical rotation measured, which was comparable to those reported for other yanuthones, altogether strongly indicating the absolute stereochemistry of C13, C14 and C15 is similar to other yanuthones.

Labeling studies confirm that yanuthones $\mathrm{K}-\mathrm{M}$ are class I yanuthones, and yanuthone $\mathrm{X}_{2}$ is a class II yanuthone

In previous work it was demonstrated that yanuthone $\mathrm{D}$, unlike the highly similar compound yanuthone $\mathrm{X}_{1}$, is biosynthesized from 6MSA. ${ }^{13}$ To prove that yanuthones $\mathrm{K}, \mathrm{L}$ and $\mathrm{M}$ truly are class I yanuthones and that yanuthone $\mathrm{X}_{2}$ is a class II yanuthone, the $A$. niger strain (KB1001) and a 6-MSA synthase deletion strain $(\text { yanA } \Delta)^{13}$ were analyzed for the presence of the four new yanuthones. This experiment revealed that neither yanuthone $\mathrm{K}, \mathrm{L}$ nor $\mathrm{M}$ were present in yan $A \Delta$ (data not shown) suggesting that these three compounds are class I compounds, biosynthesized using 6-MSA as a precursor. In contrast, yanuthone $\mathrm{X}_{2}$ was still present in the $y a n A \Delta$ strain, indicating that it is indeed a class II yanuthone. To further verify this, fully labeled ${ }^{13} \mathrm{C}_{8}$-MSA was fed to yanAs and $\mathrm{KB} 1001$. Yanuthone $\mathrm{L}$ was not produced under the given conditions in this experiment, but the data confirmed that 6-MSA was indeed incorporated into yanuthone $\mathrm{K}$ and M, verifying 6-MSA as the precursor (Figure 2). In contrast, no ${ }^{13} \mathrm{C}_{8}$-6-MSA was incorporated into yanuthone $\mathrm{X}_{2}$, which is in agreement with this compound being a class II yanuthone.

Yanuthones $\mathrm{K}-\mathrm{M}$ and $\mathrm{X}_{2}$ display antifungal activity

Some of the yanuthones have earlier been reported to display antimicrobial activity, ${ }^{9}$ and in our previous study we reported that several of the yanuthones showed antifungal activity toward $C$. albicans, with yanuthone $\mathrm{D}$ being the most active with an $\mathrm{IC}_{50}$ value of $3.3 \mu \mathrm{M} .{ }^{13}$ We therefore tested the four new yanuthones identified in this study for antifungal activity toward C. albicans, see Table 3. All three class I yanuthones showed antifungal activity in this assay. The strongest activities were observed with yanuthones $\mathrm{K}$ and $\mathrm{L}$, which resulted in $\mathrm{IC}_{50}$ values that were fivefold higher than that obtained with yanuthone $\mathrm{D}$. The weakest activity was obtained with yanuthones $\mathrm{M}$, which was 20-fold higher than the value obtained with yanuthone D. Importantly, yanuthone $\mathrm{X}_{2}$ also displayed an antimicrobial effect. With an $\mathrm{IC}_{50}$ value 15 -fold higher than that of yanuthone $\mathrm{D}$, it represents the first example of a bioactive class II yanuthone. This result demonstrates that there may be a pharmaceutical potential for this class of yanuthones.

Comparison of all class I yanuthone structures to their corresponding antifungal activities revealed some structure-activity relationship features that may be relevant for potency toward C. albicans. First, yanuthone $\mathrm{D}\left(\mathrm{IC}_{50}=3.3 \mu \mathrm{M}\right)$ and yanuthone $\mathrm{E}\left(\mathrm{IC}_{50}>100 \mu \mathrm{M}\right)$ only differ by the functional group at C15. In this case, a shift from of a ketone to a hydroxyl at this position is sufficient to eliminate the antimicrobial effect of the most bioactive yanuthone (see Figure 3). Inspection of the other compounds revealed that the functional group at $\mathrm{C} 15$ does have a significant impact on the potency, as $\mathrm{O}$ glycosylation increases antifungal activity (yanuthone $\mathrm{G}$ compared with yanuthone $\mathrm{F}$ ), and $\mathrm{O}$-acetylation at $\mathrm{C} 15$ also increases antifungal activity compared with hydroxylation (yanuthone $\mathrm{K}$ and $\mathrm{L}$ compared with 7-deacetoxyanuthone $\mathrm{A}$ and yanuthone $\mathrm{F}$, respectively (7deacetoxyyanuthone $\mathrm{A}$ was named by $\mathrm{Li}$ et $a .^{14}$ using another numbering system for the yanuthones than the originally suggested by Bugni et al. ${ }^{9}$ According to the latter numbering system, which has also been used here, the appropriate name for 7-deacetoxyyanuthone A would have been 22-deacetoxyyanothone A).

Table 3 The half maximal $I C_{50}$ for $C$. albicans treated with a small library of yanuthones isolated from Aspergillus niger KB1001

\begin{tabular}{|c|c|}
\hline Compound & $I C_{50}(\mu \mathrm{M})$ \\
\hline Yanuthone K (1) & $17.5 \pm 3.9$ \\
\hline Yanuthone L (2) & $17.0 \pm 1.9$ \\
\hline Yanuthone M (3) & $77.5 \pm 3.7$ \\
\hline Yanuthone $\mathrm{X}_{2}$ (4) & $51.7 \pm 4.7$ \\
\hline
\end{tabular}

a

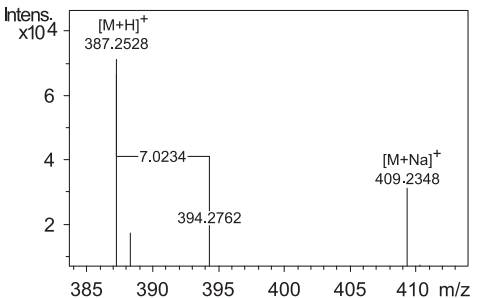

b

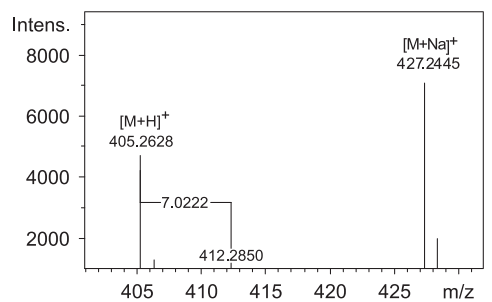

C

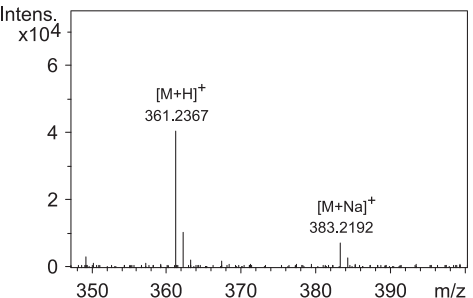

Figure 2 Positive electrospray $\left(\mathrm{ESI}^{+}\right)$mass spectrum of: (a) unlabeled and labeled yanuthone $\mathrm{K}$ (1), (b) unlabeled and labeled yanuthone $\mathrm{M}$ (3) and (c) unlabeled yanuthone $\mathrm{X}_{2}$ (4). The calculated shift from ${ }^{12} \mathrm{C}_{7}$ to ${ }^{13} \mathrm{C}_{7}$ is $7.0234 \mathrm{Da}$. 
Class I yanuthones
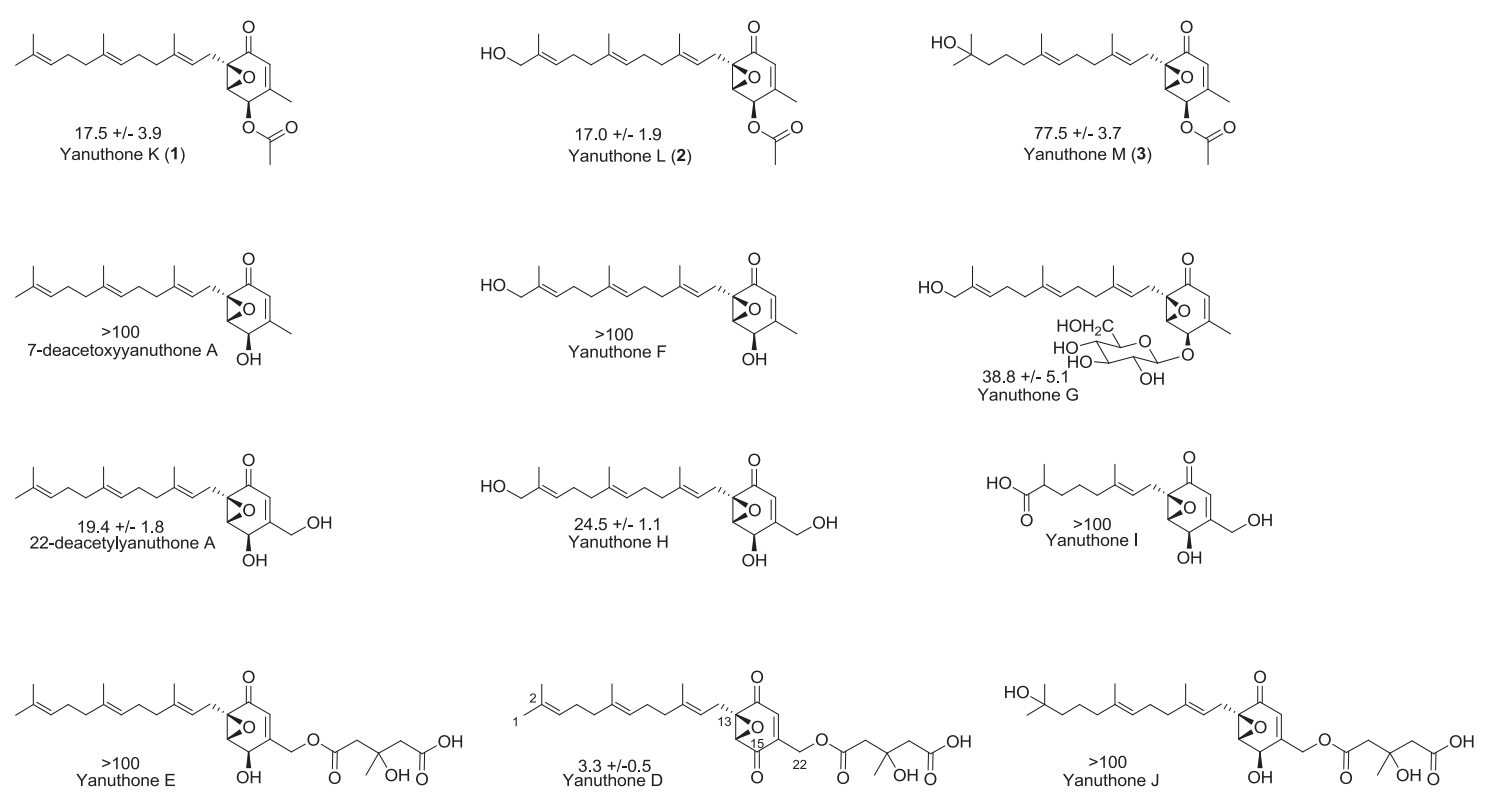

Class II yanuthones
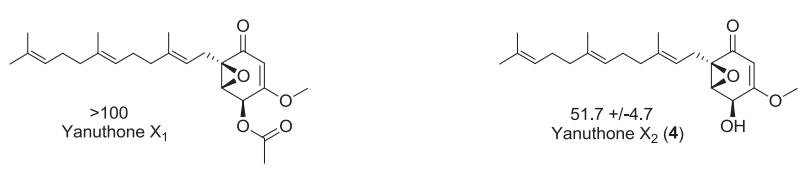

Figure 3 Overview of class I and II yanuthones as well as their $I_{50}[\mu \mathrm{m}]$ toward $C$. albicans.

Second, hydroxylation of C22 appears to increase antifungal activity. This is seen in yanuthone $\mathrm{H}\left(\mathrm{IC}_{50}=24.5 \mu \mathrm{M}\right)$ compared with yanuthone $\mathrm{F}\left(\mathrm{IC}_{50}>100 \mu \mathrm{M}\right)$, as well as in 22-deacetylyanuthone $\mathrm{A}$ $\left(\mathrm{IC}_{50}=19.4 \mu \mathrm{M}\right)$ compared with 7-deacetoxyyanuthone A $\left(\mathrm{IC}_{50}>100\right.$ $\mu \mathrm{M}$ ) (Figure 3). In both cases, the structures differ only by the C22 hydroxylation.

Last, two features seem to decrease antifungal activity: chain shortening of the sesquiterpene and hydroxylation of $\mathrm{C} 2$. Chain shortening of the sesquiterpene of yanuthone $\mathrm{I}\left(\mathrm{IC}_{50}>100 \mu \mathrm{M}\right)$ decreased antifungal activity compared with yanuthone $\mathrm{H}\left(\mathrm{IC}_{50}=24.5\right.$ $\mu \mathrm{M}$ ), which contains an intact $\mathrm{C}_{15}$ sesquiterpene (Figure 3). However, this could also be connected to the level of oxidation, and not the chain length alone. Hydroxylation of $\mathrm{C} 2$ also seems to decrease the activity, as yanuthone $\mathrm{M}\left(\mathrm{IC}_{50}=77.5 \mu \mathrm{M}\right)$ is less active than yanuthone $\mathrm{K}\left(\mathrm{IC}_{50}=17.5 \mu \mathrm{M}\right)$ (Figure 3$)$. It is unclear how $\mathrm{O}$-mevalonation at C22 affects the activity as both 7-deacetoxyyanuthone A (nonmevalonated) and yanuthone $\mathrm{E}$ (mevalonated) have $\mathrm{IC}_{50}$ values above $100 \mu \mathrm{M}$, and thus the activities were too low to be measured in this assay. The same goes for hydroxylation at $\mathrm{C} 1$, where 7deacetoxyyanuthone A (non-hydroxylated) and yanuthone F (hydroxylated) have $\mathrm{IC}_{50}$ values above $100 \mu \mathrm{M}$. On the basis of the above correlation between structures and antifungal activities, we propose that antifungal activity of class I yanuthones may increase by combining (1) oxidation of the hydroxyl group at C15 with hydroxylation of $\mathrm{C} 22$ or (2) $\mathrm{O}$-acetylation of $\mathrm{C} 15$ with hydroxylation of $\mathrm{C} 22$.

For class II yanuthones, the picture is different. In contrast to class I yanuthones, $\mathrm{O}$-acetylation at $\mathrm{C} 15$ appears to reduce antifungal activity compared with hydroxylation (Figure 3). As class II yanuthones lack the C22 carbon and have a methoxy group attached to C16 instead, there may be interplay between the side groups, which may explain this difference. As yanuthone $\mathrm{X}_{2}$, but not yanuthone $\mathrm{E}$, shows antimicrobial bioactivity, it would be of great interest to synthesize a class II yanuthone with a ketone at $\mathrm{C} 15$, to investigate whether this compound shows a stronger biological effect than yanuthone D.

In summary, a large-scale cultivation of $A$. niger has led to the discovery of four new yanuthones, which were all characterized by one-dimensional and 2D NMR spectroscopy. Labeling studies with ${ }^{13} \mathrm{C}_{8}-6$-MSA and comparison of the chemical profile of the A. niger strain (KB1001) with a 6-MSA synthase gene deletion strain (yanA $\Delta$ ) revealed three class I yanuthones (yanuthone $\mathrm{K}-\mathrm{M}$ ) originating from 6-MSA and one class II yanuthone (yanuthone $\mathrm{X}_{2}$ ) originating from a yet unknown precursor. These results were in agreement with their elucidated structures, with yanuthone $\mathrm{K}-\mathrm{M}$ containing a $\mathrm{C}_{7}$-core scaffold and yanuthone $\mathrm{X}_{2}$ a $\mathrm{C}_{6}$-core scaffold.

Furthermore, we have tested the antifungal activity of the new yanuthones toward the pathogenic yeast $C$. albicans and found that all were active. This not only shed light on the structure-activity relationships that are relevant for the potency toward C. albicans, but also demonstrated the possible pharmaceutical potential of the class II yanuthones, as yanuthone $\mathrm{X}_{2}$ represents the first example of a bioactive class II yanuthone.

\section{METHODS}

\section{Strains, media and feeding experiments}

The strains used for this study were the A. niger ATCC1015-derived KB1001 ${ }^{16}$ and the yanA $\Delta$ strain (6-MSA PKS deleted). ${ }^{13}$ Solid plates with YES media (CBS KNAW Fungal Biodiversity Centre, Utrecht, the Netherlands) were 
prepared as described by Frisvad and Samson, ${ }^{17}$ and feeding experiments with fully labeled ${ }^{13} \mathrm{C}_{8}-6$-MSA were carried out as described by Holm et al. ${ }^{13}$

\section{Chemical analysis of strains}

Strains were cultivated on solid YES media at $25^{\circ} \mathrm{C}$ for $5-7$ days in the dark. Extraction of metabolites was performed as described by Smedsgaard. ${ }^{18}$ Analysis was performed using reversed-phase ultra-HPLC UV/Vis diode array detector high-resolution time-of-flight MS on a maXis G3 orthogonal acceleration quadrupole time-of-flight mass spectrometer (Bruker Daltonics, Bremen, Germany) as described by Holm et al. ${ }^{13}$

\section{Preparative isolation of selected metabolites}

A. niger (KB1001) was cultivated on 200 plates of YES medium at $30^{\circ} \mathrm{C}$ for 5 days in the dark. Extraction, workup and fractionation were performed as described by Holm et al. ${ }^{13}$ Final purification was completed on a semipreparative HPLC system, which was a Waters 600 Controller with a Waters 996 photodiode array detector (Waters, Milford, MA, USA). This was achieved using a Luna II $\mathrm{C}_{18}$ column $(250 \times 10 \mathrm{~mm}, 5 \mu \mathrm{m}$, Phenomenex, Torrance, CA, USA) and a flow rate of $4 \mathrm{ml} \mathrm{min}^{-1}$. Solvents used were acetonitrile (ACN) of HPLC grade and milliQ-water (Merck Millipore, Darmstadt, Germany), both with 50 p.p.m. trifluoroacetic acid. For the isolation of yanuthone $\mathrm{L}, \mathrm{M}$ and $\mathrm{X}_{2}$, a gradient of $40-100 \% \mathrm{ACN}$ in $20 \mathrm{~min}$ was used, yielding $2.0,1.5$ and $1.2 \mathrm{mg}$, respectively. For isolation of yanuthone K an isocratic run with $90 \%$ ACN for $15 \mathrm{~min}$ was used, yielding $6.7 \mathrm{mg}$.

\section{NMR and structural elucidation}

The 1D and 2D spectra were recorded on a Varian Unity Inova-500 MHz spectrometer (Varian, Palo Alto, CA, USA). Spectra were acquired using standard pulse sequences, and ${ }^{1} \mathrm{H}$ spectra as well as DQF-COSY, NOESY, $\mathrm{HSQC}$ and $\mathrm{HMBC}$ spectra were acquired. The deuterated solvent was $\mathrm{CD}_{3} \mathrm{CN}-d_{3}$ and signals were referenced by solvent signals for $\mathrm{CD}_{3} \mathrm{CN}-d_{3}$ at $\delta_{\mathrm{H}}=1.94$ p.p.m. and $\delta_{\mathrm{C}}=1.32 / 118.26$ p.p.m. Chemical shifts are reported in p.p.m. $(\delta)$ and scalar couplings in hertz $(\mathrm{Hz})$. The sizes of the $J$ coupling constants reported in the tables are the experimentally measured values from the spectra. There are minor variations in the measurements that may be explained by the uncertainty of J. NMR data for all compounds including ${ }^{1} \mathrm{H}$ and 2D spectra are found in Supplementary Information. Optical rotation was measured on a Perkin Elmer 321 Polarimeter (Perkin Elmer, Waltham, MA, USA).

\section{Antifungal susceptibility testing}

All compounds were screened for antifungal activity toward C. albicans (IBT 654) in accordance with the CLSI standards, as described by Holm et al. ${ }^{13}$

\section{ACKNOWLEDGEMENTS}

The study was supported by grant 09-064967 from the Danish Council for Independent Research, Technology and Production Sciences.

1 Schuster E., Dunn-Coleman N. S., Frisvad J. C. \& Van Dijck P. W. M. On the safety of Aspergillus niger-a review. Appl. Microbiol. Biotechnol. 59, 426-435 (2002).

2 Perrone, G. et al. Biodiversity of Aspergillus species in some important agricultural products. Stud. Mycol. 59, 53-66 (2007).

3 Nielsen K. F., Mogensen J. M., Johansen M., Larsen T. O. \& Frisvad J. C. Review of secondary metabolites and mycotoxins from the Aspergillus niger group. Anal. Bioanal. Chem. 395, 1225-1242 (2009).

4 Frisvad J. C., Smedsgaard J., Samson R. A., Larsen T. O. \& Thrane U. Fumonisin B2 production by Aspergillus niger. J. Agric. Food Chem. 55, 9727-9732 (2007).

5 Mogensen J. M., Frisvad J. C., Thrane U. \& Nielsen K. F. Production of Fumonisin B2 and B4 by Aspergillus niger on grapes and raisins. J. Agric. Food Chem. 58, 954-958 (2010).

6 Noonim P., Mahakarnchanakul W., Nielsen K. F., Frisvad J. C. \& Samson R. A. Fumonisin B2 production by Aspergillus niger in Thai coffee beans. Food Addit. Contam. 26, 94-100 (2009).

7 Mogensen J. M., Larsen T. O. \& Nielsen K. F. Widespread occurrence of the mycotoxin fumonisin B2 in wine. J. Agric. Food Chem. 58, 4853-4857 (2010).

8 Knudsen P. B., Mogensen J. M., Larsen T. O. \& Nielsen K. F. Occurrence of fumonisins $\mathrm{B}(2)$ and $\mathrm{B}(4)$ in retail raisins. J. Agric. Food Chem. 59, 772-776 (2011).

9 Bugni, T. S. et al. Yanuthones: novel metabolites from a marine isolate of Aspergillus niger. J. Org. Chem. 65, 7195-7200 (2000).

10 Song, Y. C. et al. Endophytic naphthopyrone metabolites are co-inhibitors of xanthine oxidase, SW1116 cell and some microbial growths. FEMS Microbiol. Lett. 241 67-72 (2004)

11 Baker, S. E. Aspergillus niger genomics: past, present and into the future. Med. Mycol. 44, 17-21 (2006)

$12 \mathrm{Pel}, \mathrm{H}$. J. et al. Genome sequencing and analysis of the versatile cell factory Aspergillus niger CBS 513.88. Nat. Biotechnol. 25, 221-231 (2007).

$13 \mathrm{Holm}, \mathrm{D}$. K. et al. Molecular and chemical characterization of the biosynthesis of the 6 MSA derived meroterpenoid yanuthone $\mathrm{D}$ in Aspergillus niger. Chem. Biol. 21, 519-529 (2014).

$14 \mathrm{Li}$ X., Choi H. D., Kang J. S., Lee C.-O. \& Son B. W. New polyoxygenated farnesylcyclohexenones, deacetoxyyanuthone $A$ and its hydro derivative from the marine-derived fungus Penicillium sp. J. Nat. Prod. 66, 1499-1500 (2003).

15 Richards M. \& Edwards J. Nosocomial infections in combined medical-surgical intensive care units in the United States. Infect. Control Hosp. Epidemiol. 21: 510-515 (2000)

16 Chiang, Y.-M. et al. Characterization of a polyketide synthase in Aspergillus niger whose product is a precursor for both dihydroxynaphthalene (DHN) melanin and naphtho- $\gamma$ pyrone. Fungal Genet. Biol. 48, 430-437 (2011).

17 Samson R. A., Houbraken J., Thrane U., Frisvad J. C. \& Andersen B. Food and Indoor Fungi (CBS KNAW Fungal Biodiversity Centre, Utrecht, the Netherlands, 2010).

18 Smedsgaard, J. Micro-scale extraction procedure for standardized screening of fungal metabolite production in cultures. J. Chromatogr. A 760, 264-270 (1997).

Supplementary Information accompanies the paper on The Journal of Antibiotics website (http://www.nature.com/ja) 